Article

\title{
Comparative Studies of Quaternary Ammonium Salts on the Aggregation and Dispersion Behavior of Kaolinite and Quartz
}

\author{
Hao Jiang ${ }^{1, *}$, Guoyuan Xiang ${ }^{1}$, Sultan Ahmed Khoso ${ }^{1}$, Jiahui Xie ${ }^{1}$, Kai Huang ${ }^{1}$ \\ and Longhua $\mathrm{Xu}^{2}$ (D) \\ 1 School of Minerals Processing and Bioengineering, Central South University, Changsha 410083, China \\ 2 Key Laboratory of Solid Waste Treatment and Resource Recycle Ministry of Education, Southwest University \\ of Science and Technology, Mianyang 610000, China \\ * Correspondence: jianghao-1@126.com; Tel.: +86-731-8883-0545
}

Received: 10 June 2019; Accepted: 28 July 2019; Published: 31 July 2019

\begin{abstract}
Fine particles in the presence of flotation reagents exhibit different dispersion and aggregation behaviors in a mineral suspension, and affect the flotation separation processes. In this study, the effects of three quaternary ammonium salts (i.e., dodecyltrimethylammonium chloride (DTAC), tetradecyltrimethylammonium chloride (TTAC), and hexadecyltrimethylammonium chloride (CTAC)) on the dispersion and aggregation behaviors of kaolinite and quartz were studied. The mechanism was systematically investigated using sedimentation tests, reagent adsorption analysis, zeta potential measurements, and SEM analysis. In the absence of reagents, the kaolinite and quartz particles exhibited good aggregation behaviors at acid and neutral $\mathrm{pHs}$ compared with alkaline conditions. Except for CTAC, the presence of DTAC and TTAC improved the aggregation behavior of both minerals in neutral and alkaline conditions. More, the sedimentation yields of both minerals were increased significantly with increasing the concentration of DTAC and TTAC. However, the increasing concentration of CTAC resulted in an increase in the dispersion of kaolinite and quartz particles under the same conditions. At neutral and alkaline conditions, the zeta potentials and adsorbed amounts of all three salts on the mineral surfaces were increased significantly with increasing the concentrations of salts, and the adsorbed amount adopted the following sequence: CTAC > TTAC > DTAC. The zeta potential results showed that the stronger adsorption of quaternary ammonium salts on mineral surfaces at neutral and alkaline conditions was mainly because of electrostatic interactions.
\end{abstract}

Keywords: quaternary ammonium salts; kaolinite; quartz; aggregation; dispersion

\section{Introduction}

Kaolinite, as a valuable industrial mineral, plays an essential role in many advanced industries, such as papermaking [1,2], sewage treatment [3-5], biotechnology [6], pharmaceuticals, and cosmetics [7]. Quartz, which is one of the most abundant minerals in the Earth's crust, can be used both as a bulk product (e.g., quartz sands in the glass or foundry industry) and as a high-tech material (e.g., piezo or optical quartz) $[8,9]$. At the same time, the research on kaolinite and quartz is also a very important prospect in mineral processing. However, in some natural materials such as coal [10], iron [11], and diasporic bauxite [12-15], kaolinite and quartz are considered gangue minerals, and are required to be removed in the early stage processes using appropriate methods.

So far, flotation is still the most recognized method for the separation of kaolinite and quartz from valuable minerals. During a flotation process, many kinds of interaction forces, such as Van der Waals 
force and electrostatic force, are involved, in which the mineral particles show different dispersion and aggregation behaviors. Previous research has showed that the $\mathrm{pH}$ of pulp plays a vital role in the dispersion and aggregation behaviors of fine kaolinite particles $[16,17]$. It was found that the basal plane and edge plane of the kaolinite particles strongly aggregated under acidic to neutral conditions. However, the basal plane and edge plane of the kaolinite particles showed dispersion under alkaline conditions. Taking advantage of atomic force microscopy (AFM), further research on the surface charged density of the silica and alumina surfaces of the kaolinite particles were conducted $[17,18]$. The aluminum-oxygen octahedron surface was found to be positively charged at $\mathrm{pH}<6$ and negatively charged at $\mathrm{pH}>8$, whereas, the silicon-oxygen tetrahedron surface remained negatively charged at $\mathrm{pH}>4$. Mineral particles with the same charges repel each other, and particles with different charges attract each other; as a result, mineral particles in the flotation pulp show different aggregation or dispersion behavior in different $\mathrm{pH}$ conditions. In addition to $\mathrm{pH}$, reagents added to the pulp system also have a significant effect on the aggregation and dispersion behavior of mineral particles. Rao et al., found that the kaolinite particles in an aqueous aluminum salt solution only coagulated at a medium $\mathrm{AlCl}_{3}$ concentration, and formed a stable dispersion at a high salt concentration, which is mainly caused by the Stern-layer adsorption of hydrolyzed aluminum species on the kaolinite surface [19]. Lagaly and Ziesmer studied the coagulation of sodium montmorillonite dispersions by inorganic and organic cations, and the influence of some compounds of practical interest, such as phosphates, and cationic and anionic surfactants [20]. They found that coagulation mainly occurs between the negative edges and the negative face in most cases. Phosphates, polyphosphate, and tannate increased the edge charge density and changed the type of coagulation.

As far as the authors know, the aggregation and dispersion behavior of kaolinite and quartz in a quaternary ammonium cationic surfactant system has been rarely documented. Quaternary ammonium salts, with the structural feature of four alkyl groups attached to a central cationic nitrogen atom $\left(\mathrm{R}_{4} \mathrm{~N}^{+}\right)$, are perpetually charged, regardless of the solution $\mathrm{pH}$ [21]. Therefore, as strong cationic surfactants, the properties of quaternary ammonium salts are almost unchanged in different solution conditions. However, the properties of quaternary ammonium salts with different carbon chain lengths are quite different. Our previous research has investigated the flotation behaviors of kaolinite in the presence of different quaternary ammonium salts, such as decyltrimethylammonium (103C), dodecyltrimethylammonium chloride (DTAC), tetradecyltrimethylammonium chloride (TTAC), and cetyltrimethylammonium chloride (CTAC) [22]. We found that, the longer the hydrocarbon chain of the surfactant, the more likely it was to be adsorbed by fine kaolinite particles, which led to a lower flotation recovery. However, the effect of quaternary ammonium salts on the aggregation and dispersion behavior of kaolinite has not been studied yet.

Kaolinite $\left[\mathrm{Al}_{2} \mathrm{O}_{3} \cdot 2 \mathrm{SiO}_{2} \cdot 2 \mathrm{H}_{2} \mathrm{O}\right]$ has a 1:1 structure, with a single layer of the crystal structure composed of an aluminum-oxygen octahedron and silicon-oxygen tetrahedron, with the adjacent layers held together by hydrogen bonding $[23,24]$. Quartz $\left[\mathrm{SiO}_{2}\right]$ is a lattice crystal composed of a silicon-oxygen tetrahedron, in which each silicon atom is connected with four oxygen atoms by four single bonds to form a silicon-oxygen tetrahedron [25]. On the one hand, the crystal structure of kaolinite and quartz has one thing in common, namely the silicon-oxygen tetrahedron. On the other hand, under a low $\mathrm{pH}$, we found that the kaolinite particles were spontaneously aggregated, while the quartz particles were dispersed. Therefore, a comparative study on the dispersion and aggregation behavior of kaolinite and quartz has a certain guiding significance for the subsequent flotation. In this study, the dispersion and aggregation of typical silicon-containing minerals, kaolinite and quartz, under different quaternary ammonium salts were investigated. The adsorption mechanism of the quaternary ammonium cationic surfactants on these two kinds of mineral surfaces, together with the dispersion and aggregation behavior, are discussed. 


\section{Materials and Methods}

\subsection{Materials and Chemicals}

The kaolinite and quartz samples were obtained from Xiaoyi in Shanxi Province and Donghai in Jiangsu Province, China, respectively. The samples were hand-picked, ground in a porcelain mill, and dry sieved through a 74- $\mu \mathrm{m}$ diameter screen, following by a wet sieve process through a screen with a 36- $\mu \mathrm{m}$ diameter. The undersize products were dried at a low temperature and bottled for future use. Chemical composition analysis and X-ray diffractometry (XRD) were conducted to examine the purity of the kaolinite and quartz. The results presented in Table 1 and Figure 1 show that the purity of the mineral samples was approximately $90 \%$, which satisfied the experimental demands in this work.

The specifications of the three types of quaternary ammonium salts used in this work are shown in Table 2. The dodecyltrimethylammonium chloride (DTAC; $\left.\mathrm{C}_{12} \mathrm{H}_{25}\left(\mathrm{CH}_{3}\right)_{3} \mathrm{NCl}\right)$ and tetradecyltrimethylammonium chloride (TTAC; $\mathrm{C}_{14} \mathrm{H}_{29}\left(\mathrm{CH}_{3}\right)_{3} \mathrm{NCl}$ ) were purchased from Nanjing Robiot Co., Ltd., China. The hexadecyltrimethylammonium chloride (CTAC; $\left.\mathrm{C}_{16} \mathrm{H}_{33}(\mathrm{CH})_{3} \mathrm{NCl}\right)$ was purchased from Sinopharm Chemical Reagent Co., Ltd., China. All of the reagents were in analytical grade.

Table 1. Chemical composition of the purified sample (mass fraction, \%).

\begin{tabular}{cccccccccc}
\hline Components & $\mathrm{Al}_{\mathbf{2}} \mathbf{O}_{\mathbf{3}}$ & $\mathrm{SiO}_{2}$ & $\mathrm{Fe}_{\mathbf{2}} \mathbf{O}_{\mathbf{3}}$ & $\mathrm{TiO}_{\mathbf{2}}$ & $\mathrm{CaO}$ & $\mathbf{M g O}$ & $\mathbf{K}_{\mathbf{2}} \mathbf{O}$ & $\mathbf{N a}_{2} \mathbf{O}$ & $\mathbf{L O I}^{\mathbf{a}}$ \\
\hline Kaolinite & 39.2 & 43.67 & 0.32 & 1.98 & 0.01 & 0.068 & 0.094 & 0.028 & 13.98 \\
Quartz & 0.77 & 94.95 & 0.01 & 0.01 & 0.04 & 0 & 0.01 & 0 & 3.47 \\
\hline \multicolumn{8}{c}{${ }^{\text {a }}$ Loss on ignition. }
\end{tabular}

Table 2. Specifications of the three types of quaternary ammonium salts.

\begin{tabular}{ccccc}
\hline Quaternary Ammonium Salts & Abbreviation & $\begin{array}{c}\text { Molecular } \\
\text { Formula }\end{array}$ & $\begin{array}{c}\text { Weight } \\
\text { Molecular }\end{array}$ & $\begin{array}{c}\text { Carbon Chain } \\
\text { Length }\end{array}$ \\
\hline $\begin{array}{c}\text { Dodecyltrimethylammonium } \\
\text { chloride }\end{array}$ & DTAC & $\mathrm{C}_{12} \mathrm{H}_{25}\left(\mathrm{CH}_{3}\right)_{3} \mathrm{NCl}$ & 263.90 & 12 \\
$\begin{array}{c}\text { Tetradecyltrimethylammonium } \\
\text { chloride }\end{array}$ & TTAC & $\mathrm{C}_{14} \mathrm{H}_{29}\left(\mathrm{CH}_{3}\right)_{3} \mathrm{NCl}$ & 291.94 & 14 \\
$\begin{array}{c}\text { Hexadecyltrimethylammonium } \\
\text { chloride }\end{array}$ & CTAC & $\mathrm{C}_{16} \mathrm{H}_{33}\left(\mathrm{CH}_{3}\right)_{3} \mathrm{NCl}$ & 320.00 & 16 \\
\hline
\end{tabular}
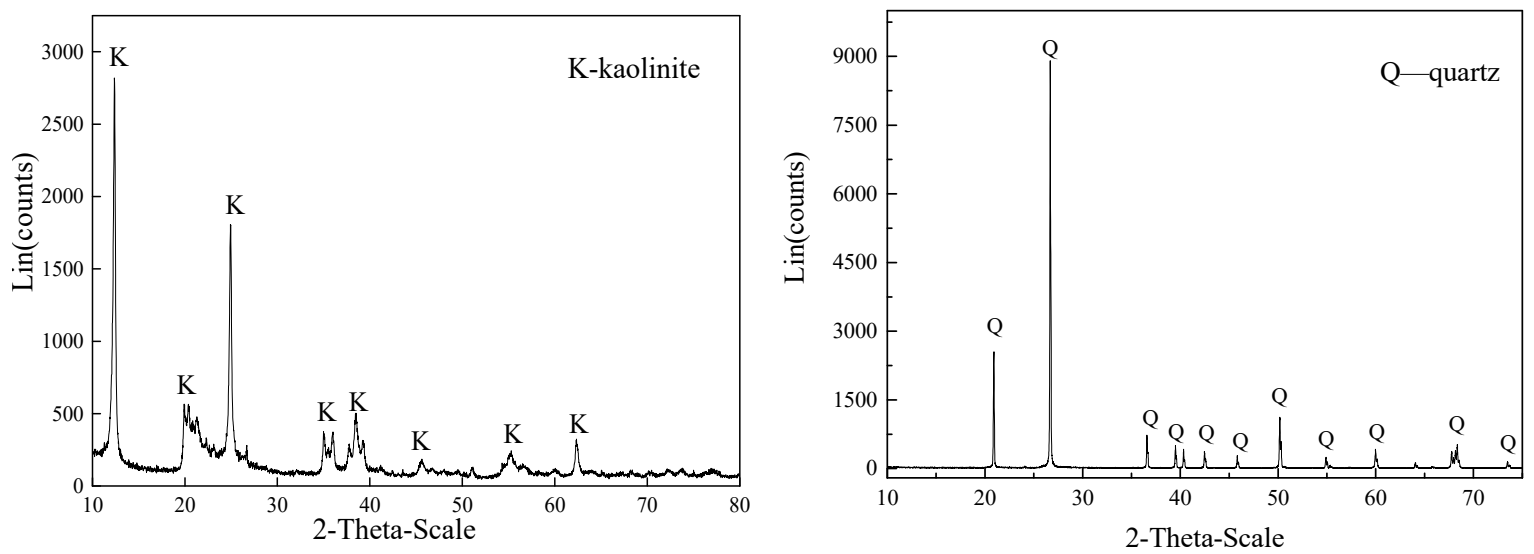

Figure 1. X-ray diffraction analysis of the kaolinite and quartz.

\subsection{Sedimentation Tests}

In each of the tests, the ore samples $(3 \mathrm{~g})$, distilled water $(150 \mathrm{~mL})$, and the required reagents were added to a $250 \mathrm{~mL}$ beaker and agitated for $5 \mathrm{~min}$ using a magnetic stirring machine. Following the $\mathrm{pH}$ adjustment with a stirring time of $2 \mathrm{~min}$, the desired reagent was added to the suspension and 
conditioned for an extra $2 \mathrm{~min}$. Afterwards, the mixture was transferred to a $250 \mathrm{~mL}$ settling bottle, at which the required volume of the distilled water $(250 \mathrm{~mL})$ and $\mathrm{pH}$ was adjusted again. The bottle was inverted 10 times, and after being left to stand for $5 \mathrm{~min}$, the supernatant was extracted using a siphon to reduce the settling height to $25 \mathrm{~mm}$. After the pulp had been left to dry in the settling bottle, it was then weighed, and the sedimentation yield of the minerals was calculated according to Equation (1).

$$
\gamma=(m / M) \times 100 \%
$$

where, $\gamma(\%)$ is the sedimentation yield, $\mathrm{m}(\mathrm{g})$ is the mass of mineral remained in the settling bottle, and $\mathrm{M}(\mathrm{g})$ is total mass of the mineral added into the bottle. Smaller values of $\gamma$ indicate a greater dispersity, whereas, larger values indicate a smaller dispersity of the mineral.

\subsection{Adsorbed Amount Measurements}

The adsorption of quaternary ammonium salts on the mineral surface was determined by using total organic carbon (TOC) measurements (TOC-LCPH Analyzer, Shimadzu, Kyoto, Japan). For this, $2 \mathrm{~g}$ of a mineral sample was placed into the $200 \mathrm{~mL}$ plexiglass filled with $40 \mathrm{~mL}$ mixed surfactant solution whose concentration is known. The suspension was agitated for $40 \mathrm{~min}$ in a vapor-bathing vibrator, and then centrifuged at $9000 \mathrm{r} / \mathrm{min}$ for $30 \mathrm{~min}$. Finally, the supernatant was collected for the TOC measurements. All of the TOC experiments were performed at $25^{\circ} \mathrm{C}$.

The results of the TOC measure were transferred to the molar concentration, and the adsorption of the quaternary ammonium salts on the mineral surface was calculated according to Equation (2).

$$
\Gamma=\left(C_{0}-C\right) \cdot V / m
$$

where, $\Gamma$ is the adsorption $(\mathrm{mol} / \mathrm{g}), C_{0}(\mathrm{~mol} / \mathrm{L})$ and $C(\mathrm{~mol} / \mathrm{L})$ are the initial and supernatant concentration, respectively; $V(\mathrm{~L})$ is the volume of the solution; and $m(\mathrm{~g})$ is the mineral mass.

\subsection{Zeta Potential Measurements}

Zeta potential measurements were conducted using a zetasizer (Zetasizer Nano Z, Malvern Instruments Ltd., UK). Ore samples $(0.06 \mathrm{~g})$, with a particle size of less than $5 \mu \mathrm{m}$, and distilled water $(50 \mathrm{~mL})$, were added to a $100-\mathrm{mL}$ beaker and stirred using a magnetic stirrer for $5 \mathrm{~min}$. Following the $\mathrm{pH}$ adjustment by $\mathrm{HCl}$ or $\mathrm{NaOH}$ with a stirring time of $2 \mathrm{~min}$, the desired reagent was added to the suspension and conditioned for an extra $2 \mathrm{~min}$. After being left to settle for $5 \mathrm{~min}$, a small amount of supernatant was drawn from the sample for the zeta potential measurements. Each measurement was repeated six times, and an average value was calculated from the data.

\subsection{SEM Measurements}

The morphology of the mineral samples before and after the adsorption of reagents was observed by scanning electron microscopy (Helios Nanolab 600, FEI Corporation, Hillsboro, Oregon, USA).

Ore samples $(0.6 \mathrm{~g})$ and distilled water $(50 \mathrm{~mL})$ were added to a $100-\mathrm{mL}$ beaker and stirred using a magnetic stirrer for $5 \mathrm{~min}$. Following the $\mathrm{pH}$ adjustment by $\mathrm{HCl}$ or $\mathrm{NaOH}$ with a stirring time of $2 \mathrm{~min}$, the desired reagent was added to the suspension, and conditioned for extra $2 \mathrm{~min}$. By using a syringe, $2.5 \mathrm{~mL}$ of the pulp was drawn from the mixture and diluted 20 times while maintaining a constant $\mathrm{pH}$. One drop (diameter of ca. $5 \mathrm{~mm}$ ) of the diluted solution was placed onto a glass slide using a $5 \mathrm{~mL}$ syringe. After the samples had dried, they were spray coated with a layer of platinum.

\section{Results and Discussion}

\subsection{The Effect of Quaternary Ammonium Salts on Sedimentation Behavior of Kaolinite and Quartz}

Different mineral particles possess different dispersion and aggregation behaviors that significantly affect their separation mechanism. For example, in the reverse flotation of bauxite, the dispersion 
and aggregation behavior of the pulp suspension plays a crucial role in the selective separation of silicate minerals [26]. Therefore, in this section, the sedimentation behaviors of kaolinite and quartz at different $\mathrm{pHs}$, concentrations, and carbon chain lengths of quaternary ammonium salts were discussed.

Figure 2 shows the effect of $\mathrm{pH}$ on the sedimentation and aggregation behaviors of kaolinite and quartz. As shown, the kaolinite particles exhibited a strong aggregation from an acid to natural $\mathrm{pH}$, and their sedimentation yields were consistently above $90 \%$ in a wide $\mathrm{pH}$ range of $2-8$. Compared with kaolinite, the sedimentation yields of the quartz particles were quite low, and decreased further from $60 \%$ to $25 \%$ when the solution $\mathrm{pH}$ was increased from 2 to 12 . In alkaline conditions, both minerals exhibited dispersion behaviors; however, the quartz particles were dispersed significantly more than the kaolinite ones.

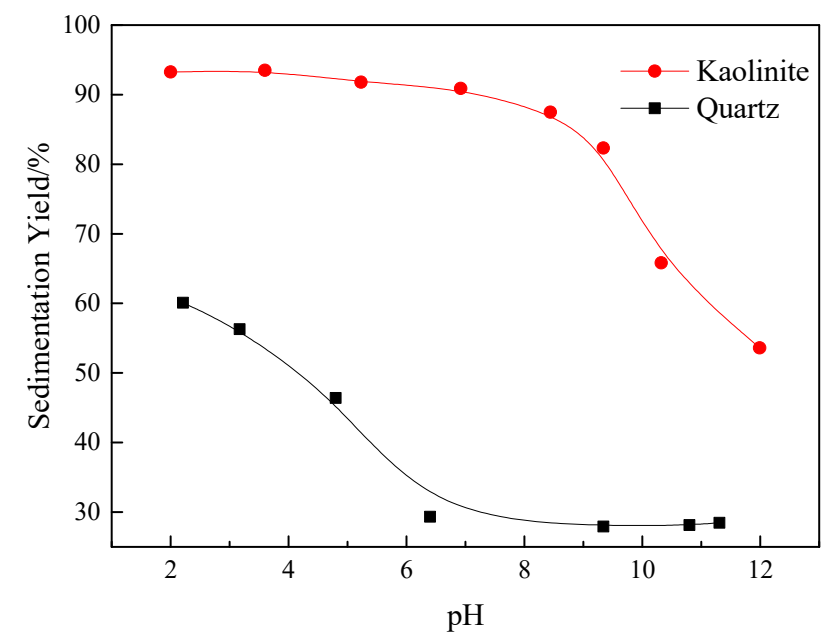

Figure 2. Sedimentation yields of kaolinite and quartz as a function of $\mathrm{pH}$.

Figure 3 shows the effect of different concentrations of three quaternary ammonium salts on the sedimentation behavior of kaolinite and quartz at a nearly neutral condition ( $\mathrm{pH}$ 6.7). As shown in Figure $3 a$, the increasing concentration of DTAC and TTAC continuously increased the sedimentation yields of the kaolinite particles, indicating that both surfactants had a better aggregation effect on kaolinite. However, TTAC exhibited a stronger aggregation effect than DTAC, the reason for which may be the longer carbon chain of TTAC in comparison to DTAC. CTAC, on the other hand, showed quite different sedimentation behavior from DTAC and TTAC. Firstly, kaolinite showed an increasing trend of sedimentation yields with the increasing concentration of CTAC from 0 to $8 \times 10^{-4} \mathrm{M}$. However, as the concentration was increased from $8 \times 10^{-4} \mathrm{M}$, kaolinite exhibited a decreasing trend of sedimentation yields. This indicates a boundary from the aggregation to dispersion of the kaolinite particles.

As shown in Figure $3 b$, all of the three quaternary ammonium salts exhibited different effects on the quartz particles. The increasing concentration of DTAC increased and achieved stable sedimentation yields of quartz of greater than $90 \%$. In the case of TTAC, sedimentation increased rapidly to a maximum value of $95 \%$, after which it decreased gradually to $74 \%$. The sedimentation yield of quartz increased with the increasing concentration of CTAC, and peaked at the concentration of $1 \times 10^{-4} \mathrm{M}$. A further increase to $1.2 \times 10^{-3} \mathrm{M}$ resulted in a reduction to $27 \%$ where the quartz particles completely dispersed. These results indicate that under neutral conditions, quartz particles exhibited a strong aggregation at low concentrations of all three salts. When the concentration of TTAC and CTAC was increased beyond $1 \times 10^{-4} \mathrm{M}$, the quartz particles gradually dispersed. Finally, CTAC exhibited stronger effects on the quartz particles than TTAC. 


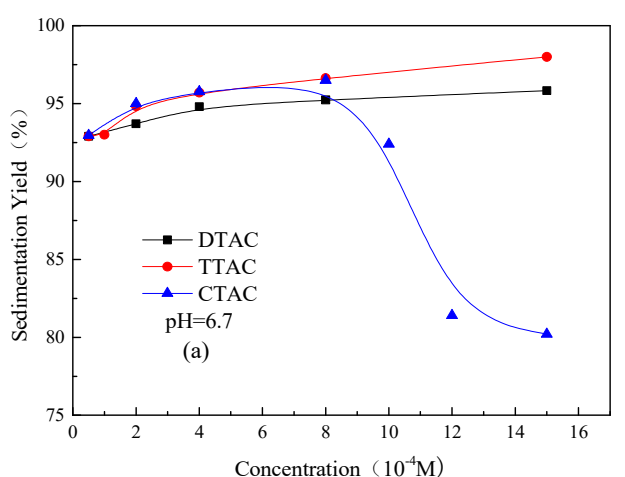

(a)

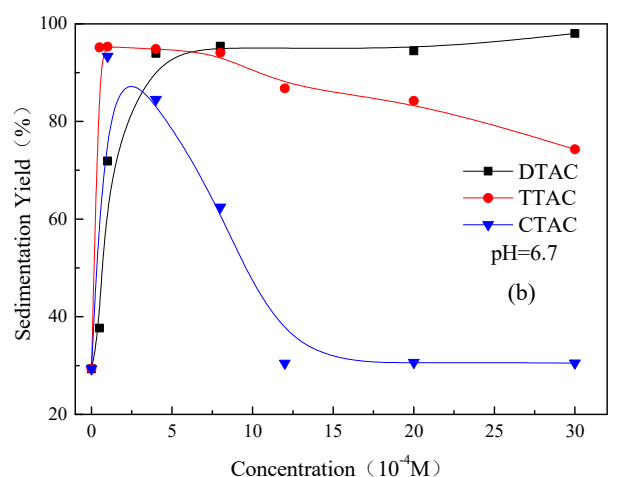

(b)

Figure 3. Sedimentation yields of kaolinite (a) and quartz (b) as a function of different concentrations of quaternary ammonium salts at $\mathrm{pH} 6.7$.

Figure 4 shows the effect of different concentrations of three quaternary ammonium salts on the sedimentation behavior of kaolinite and quartz at $\mathrm{pH} 10$. As can be observed in Figure 4a, the sedimentation yield of the kaolinite particles was increased with the increasing concentration of all three of the quaternary ammonium salts. However, at a concentration above of $4 \times 10^{-4} \mathrm{M}$, the sedimentation yield remained stable and unchanged. However, if the concentration is kept constant, the carbon chain length of the salts becomes the defining factor for the sedimentation yield of kaolinite, and can be placed in the following order of effectiveness: CTAC > TTAC > DTAC.

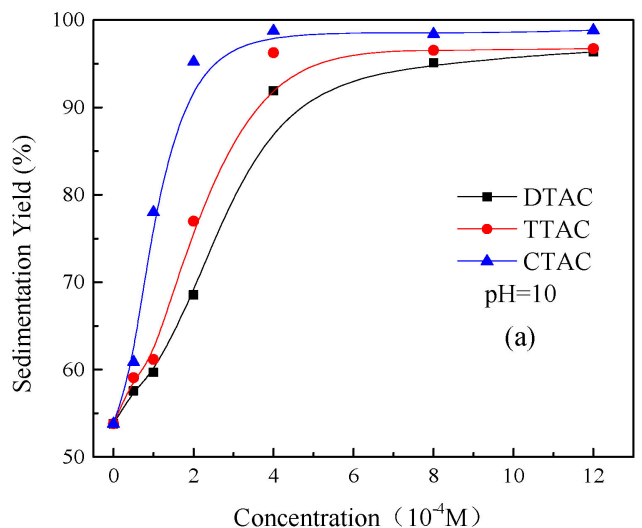

(a)

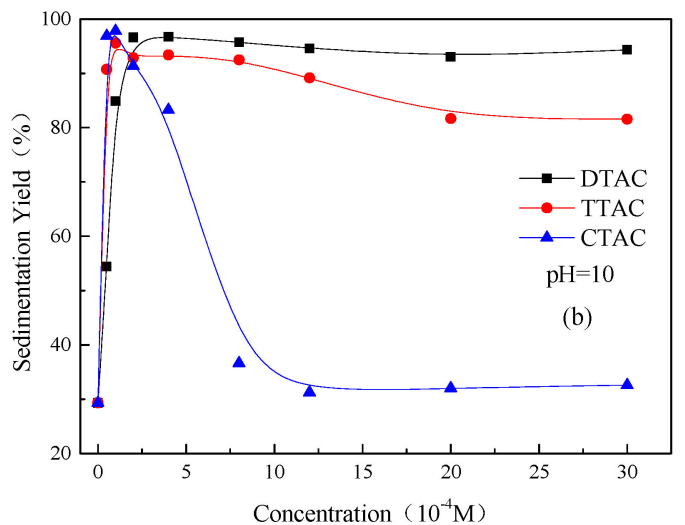

(b)

Figure 4. Sedimentation yields of kaolinite (a) and quartz (b) as a function of the different concentrations of quaternary ammonium salts at $\mathrm{pH} 10$.

Figure $4 \mathrm{~b}$ reveals that the influence of three quaternary ammonium salts on the dispersion and aggregation behaviors of quartz at $\mathrm{pH} 10$ was the same as that observed at $\mathrm{pH} 6.7$ (Figure 3b). However, compared to the results shown in Figure $3 b$, it can be observed that the concentrations of CTAC required for the complete dispersion were decreased from $1.2 \times 10^{-3} \mathrm{M}$ to $8 \times 10^{-4} \mathrm{M}$. These results show that, at an alkaline $\mathrm{pH}$, the quartz particles exhibited a strong aggregation, even at lower concentrations of DTAC. However, when the concentration of CTAC was reached at $8 \times 10^{-4} \mathrm{M}$, the dispersity of the quartz showed a great improvement. Finally, the CTAC concentration required for the complete dispersion of the quartz particles was lower than that observed under neutral conditions. 


\subsection{Adsorption of Quaternary Ammonium Salts on Kaolinite and Quartz Surfaces}

It is reported that the hemi-micelle theory is based on the adsorption of amine ions on the surface of quartz $[27,28]$. The adsorption model proposed by Somasundaran et al. is particularly successful in describing the adsorption of cationic surfactants on the surface of bauxite [29]. Their investigation divided the adsorption isotherm into four different regions (regions i-iv), where surfactants show different adsorption behaviors on mineral surfaces. In region (i), the surfactant in the form of a monomer is adsorbed by electrostatic attraction. In region (ii), the adsorption of the surfactants occurs in the form of hemi-micelle. In region (iii), the adsorption of surfactants on the surface of the minerals continues, and the adsorption of a second molecular layer gradually formed. Finally, in region (iv), that is, the stationary region of the adsorption isotherm, the surfactant on the surface of the mineral takes the form of a double layer adsorption.

Figure 5 shows the Zeta potentials and adsorbed amounts on kaolinite surface as a function of the different concentrations of quaternary ammonium salts at a neutral $\mathrm{pH}$. As can be noted, the adsorption amount analysis closely followed the Zeta potential measurements. The increasing concentration of all three salts increased the Zeta potentials of the kaolinite particles towards a more positive side. Similarly, the adsorbed amount of all three salts on the kaolinite surface was increased with increasing their concentration. Moreover, the adsorption affinity of the quaternary ammonium salts was closely related to the length of their carbon chain; the longer the carbon chain, the stronger the adsorption affinity.

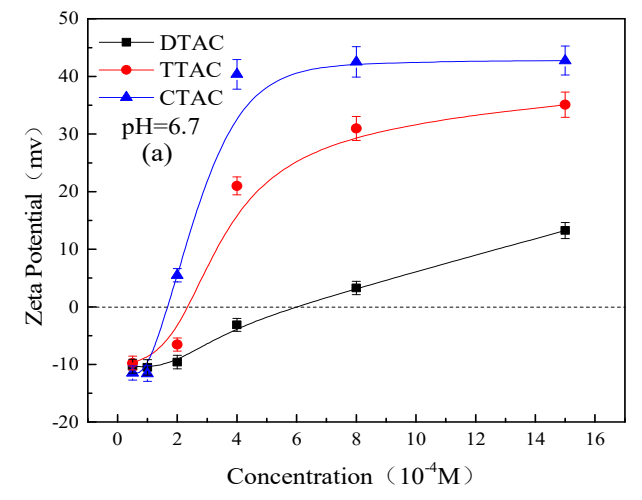

(a)

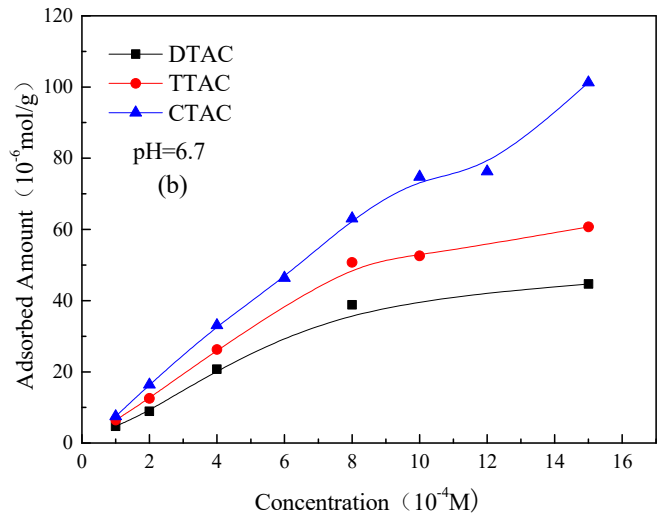

(b)

Figure 5. Zeta potentials (a) and adsorbed amounts (b) on kaolinite surface as a function of different concentrations of quaternary ammonium salts at $\mathrm{pH}$ 6.7.

Figure 6 shows the Zeta potentials and adsorbed amounts on the kaolinite surface as a function of the different concentrations of quaternary ammonium salts at alkaline conditions. It can be observed, that the increasing concentration of all three salts increased both the Zeta potentials and their amount of adsorption on the surface of kaolinite. However, compared with neutral conditions (Figure 5a), the adsorbed amount of salts at alkaline conditions was much larger. The greater adsorption of salts at alkaline conditions was mainly due to the highly negative surface of kaolinite, while at neutral conditions, the kaolinite surface was positive, which electrostatically repulsed the surrounding salts. 


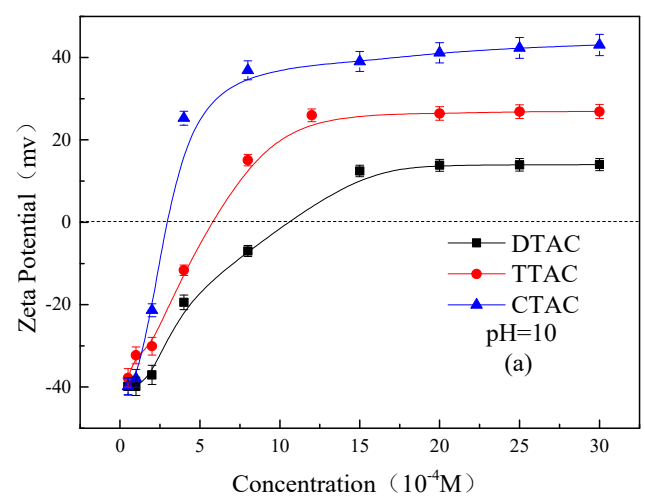

(a)

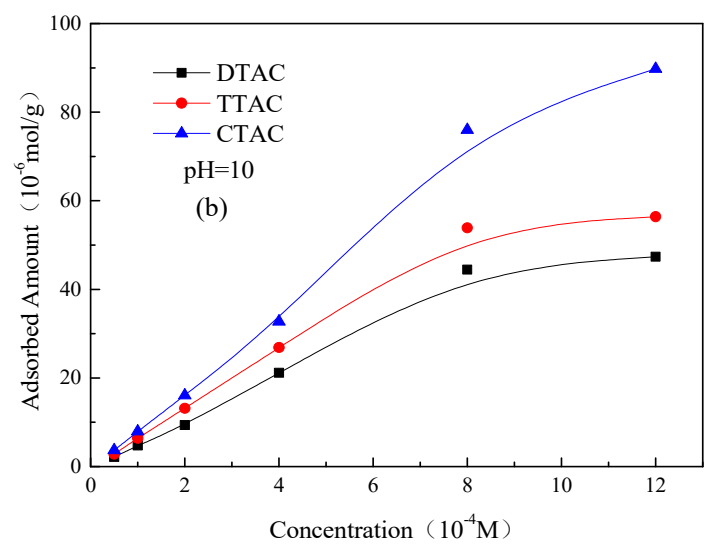

(b)

Figure 6. Zeta potentials (a) and adsorbed amounts (b) on kaolinite surface as a function of different concentrations of quaternary ammonium salts at $\mathrm{pH} 10$.

The Zeta potentials and adsorbed amount of salts on the quartz surface as a function of the different concentrations of quaternary ammonium salts at a neutral condition are shown in Figure 7 . Both the Zeta potentials and adsorbed amounts of all three salts were increased significantly with increasing their concentrations, and the adsorbed amount adopted the following sequence: CTAC > TTAC > DTAC. Initially the adsorbed amount of salts on the quartz particles showed a rapid rise with the increasing concentration, and then exhibited a slower increase once the concentration was reached at $8 \times 10^{-4} \mathrm{M}$. This indicates that the TTAC molecule layer began to form at a concentration of $8 \times 10^{-4}$ $M$. The adsorbed amount of CTAC on the quartz surface increased rapidly and remained stable at concentrations $>1.2 \times 10^{-3} \mathrm{M}$, as did the sedimentation yield. This indicates that the CTAC molecule layer on the quartz had become saturated.

It is observed from Figure 8 that the alkaline samples showed a greater adsorbed amount in comparison to that of the neutral samples. This may be attributed to the highly negative surface of the quartz particles at an alkaline condition, which strengthens the electrostatic interactions between the quartz particles and quaternary ammonium salts.

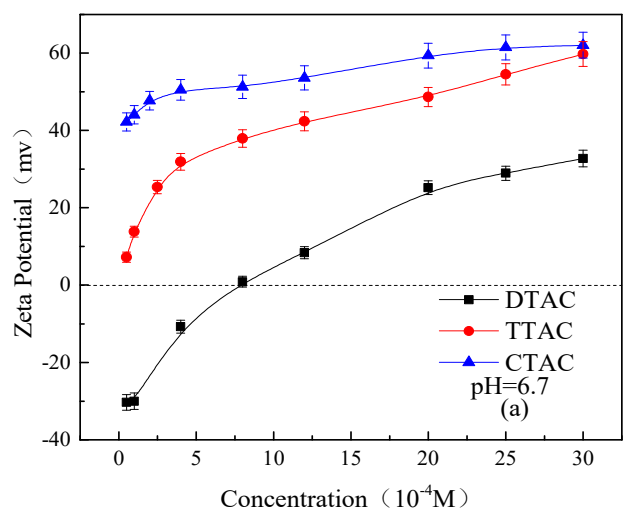

(a)

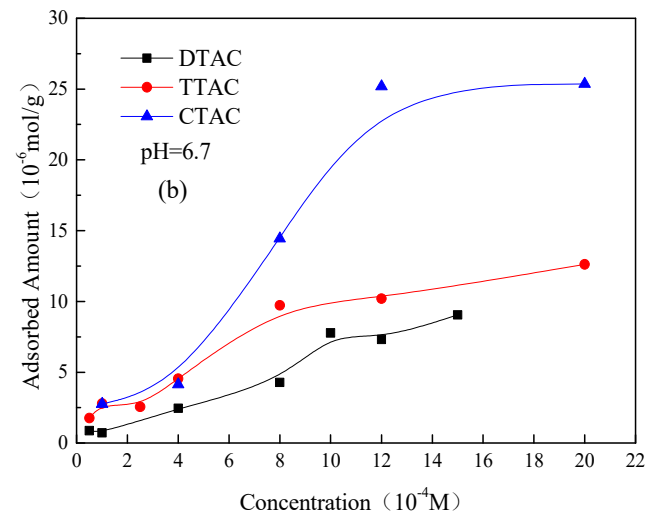

(b)

Figure 7. Zeta potentials (a) and adsorbed amounts (b) on the quartz surface as a function of different concentrations of quaternary ammonium salts at $\mathrm{pH}$ 6.7. 


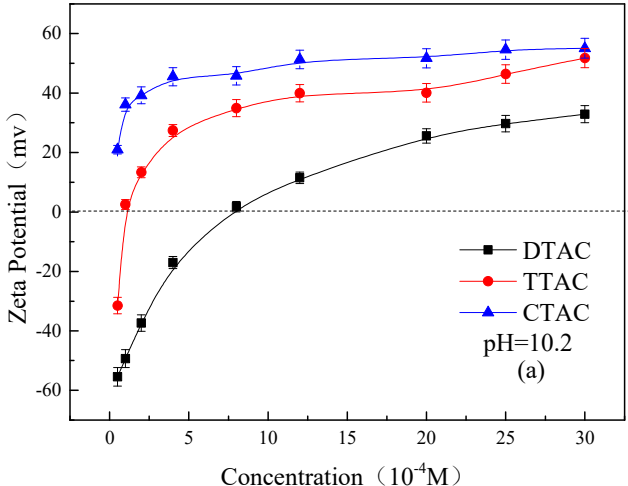

(a)

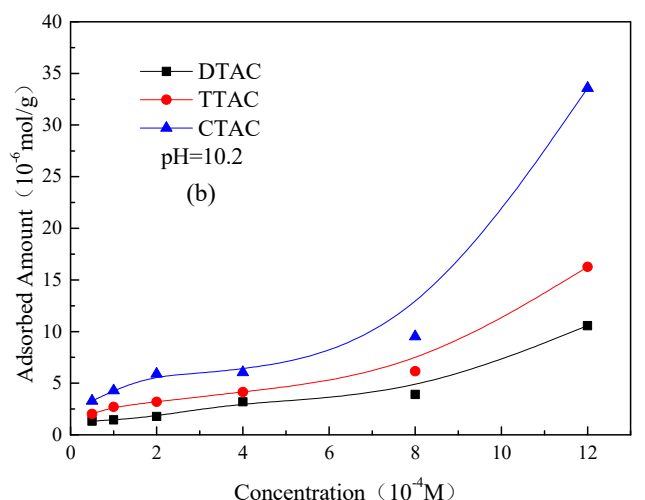

(b)

Figure 8. Zeta potentials (a) and adsorbed amounts (b) on a quartz surface as a function of different concentrations of quaternary ammonium salts at $\mathrm{pH} 10.2$.

\subsection{SEM Image Analysis}

Figure 9 shows the SEM micrographs of kaolinite under neutral and acid conditions in the absence of ammonium salts. As shown in the micrographs, kaolinite exhibited a pronounced lamellar structure at acid conditions. Therefore, the strong aggregation of kaolinite at acid conditions was mainly due to the presence of a lamellar form, and the aggregation occurred from either the basal to basal plane, or the edge to basal plane. Figure $9 \mathrm{~b}$ shows that the aggregation also occurred at neutral conditions; however, it was not as pronounced as that at the acidic samples. The kaolinite aggregates mainly occurred between the basal planes. Marek et al. proposed that nano-scale micro-bubbles existed on the hydrophobic surface of clay minerals, which was later confirmed by AFM $[18,30,31]$. Because of the existence of broken bonds at the edge of the surface, kaolinite may absorb on the micro-bubbles that present in the water. The bubbles create a bridging effect, which results in long-range hydrophobic attractions across the basal plane of the kaolinite structure and increases their aggregation.
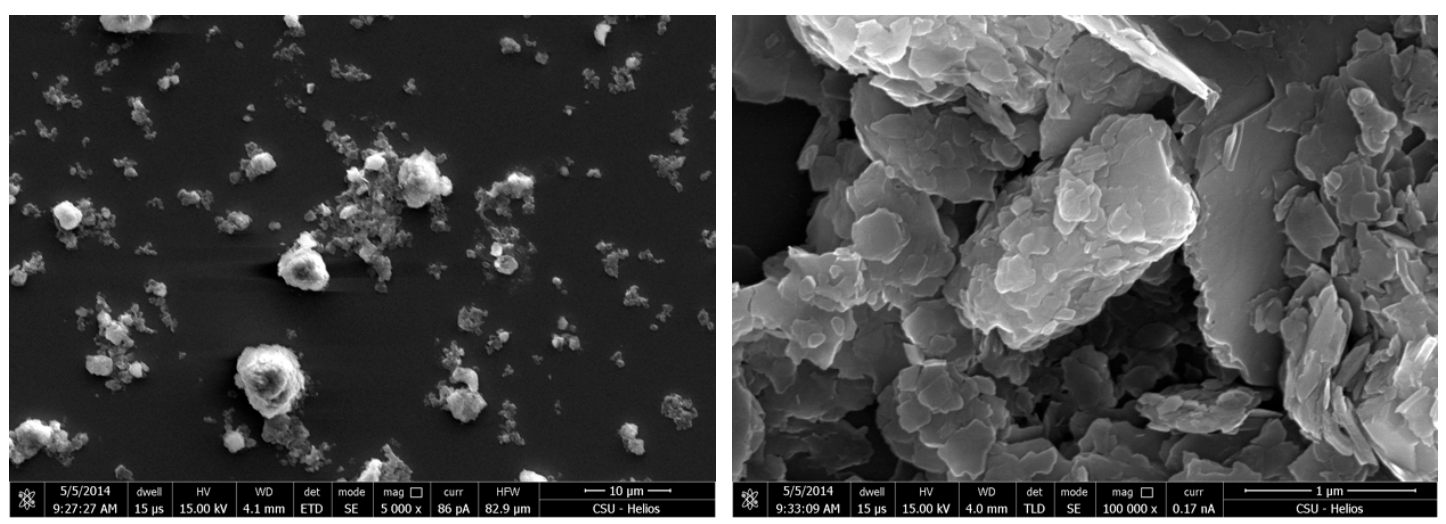

(a)

Figure 9. Cont. 

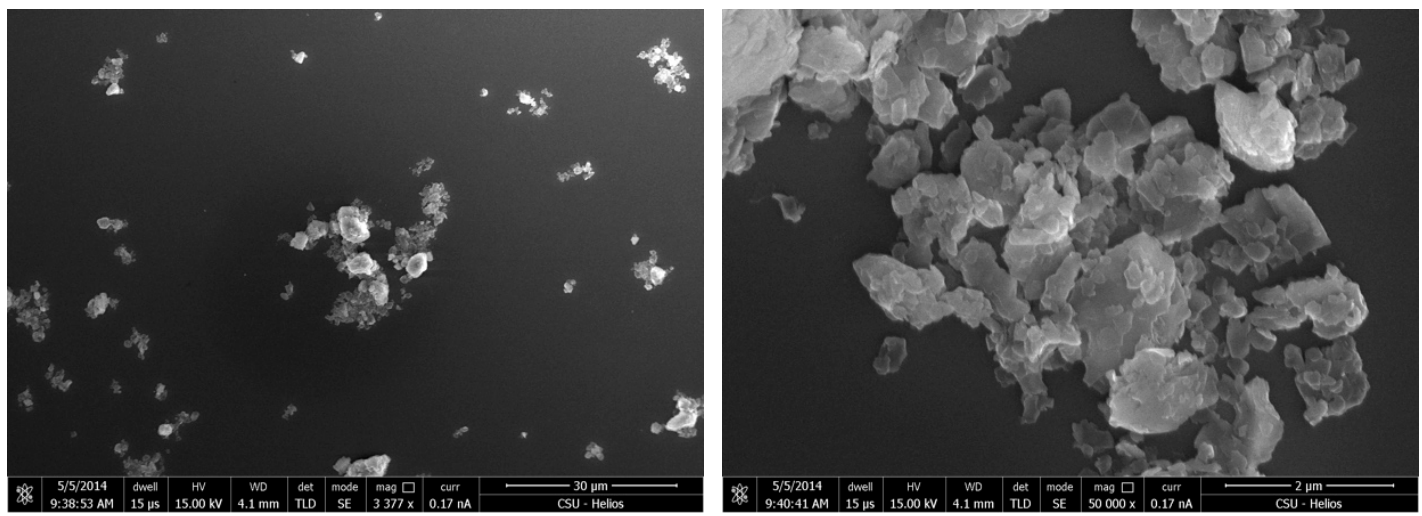

(b)

Figure 9. SEM micrographs at different magnifications of kaolinite treated at different $\mathrm{pH}$ levels. (a) $\mathrm{pH}=2.3(\mathbf{b}) \mathrm{pH}=6.7$.

The SEM micrographs of kaolinite in the presence of quaternary ammonium salts at different $\mathrm{pH}$ conditions are shown in Figures 10-12. As the aggregation occurred via the basal or edge planes of the kaolinite structure where the adsorption energy of quaternary ammonium salts on the (001) face is lower than that of the (001) face. Thus, the effect of the quaternary ammonium salts on the (001) face under the effect of special affinity can be seen from Figure 10.

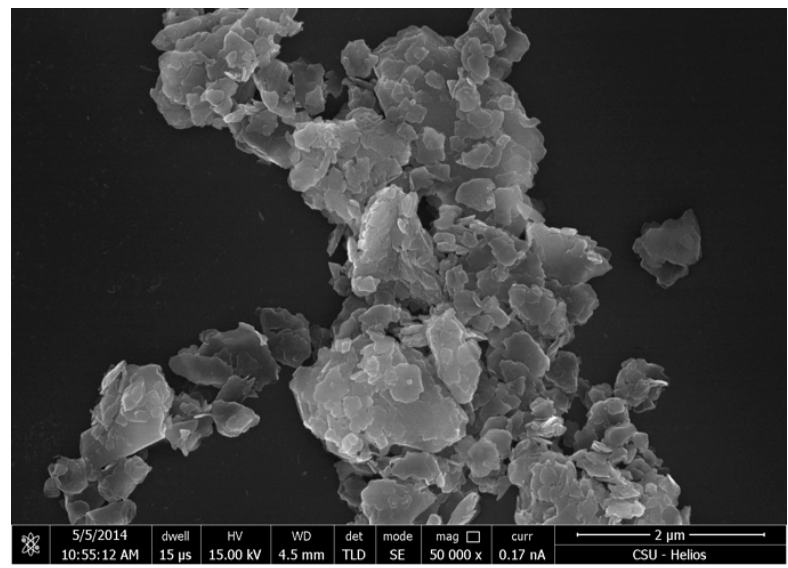

Figure 10. SEM micrograph of kaolinite with $2 \times 10^{-4} \mathrm{M} \mathrm{CTAC}$ at $\mathrm{pH} 2.4$.

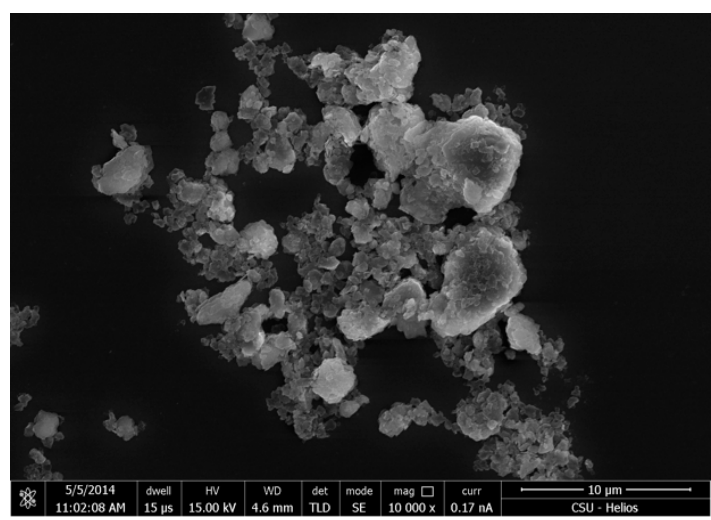

(a)

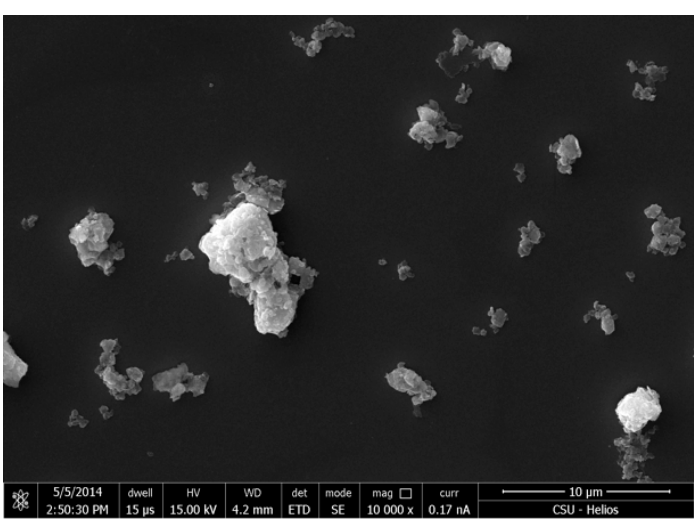

(b)

Figure 11. SEM micrographs of kaolinite with $1.2 \times 10^{-3} \mathrm{M}$ quaternary ammonium salts under neutral condition (a) using dodecyltrimethylammonium chloride (DTAC) and (b) hexadecyltrimethylammonium chloride (CTAC). 


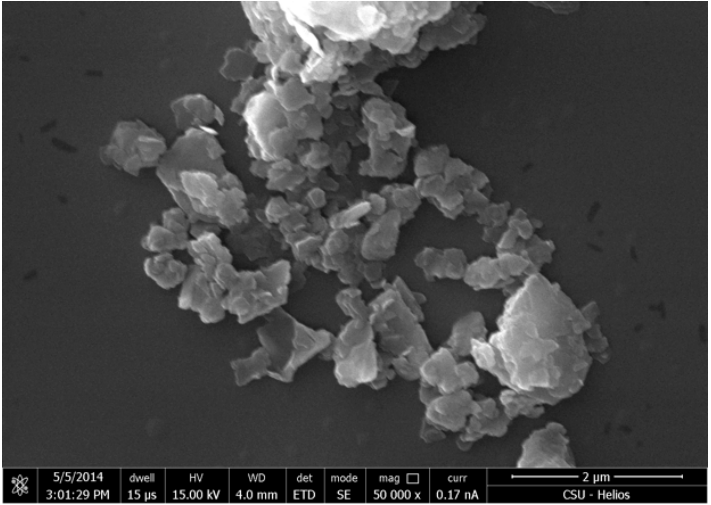

(a)

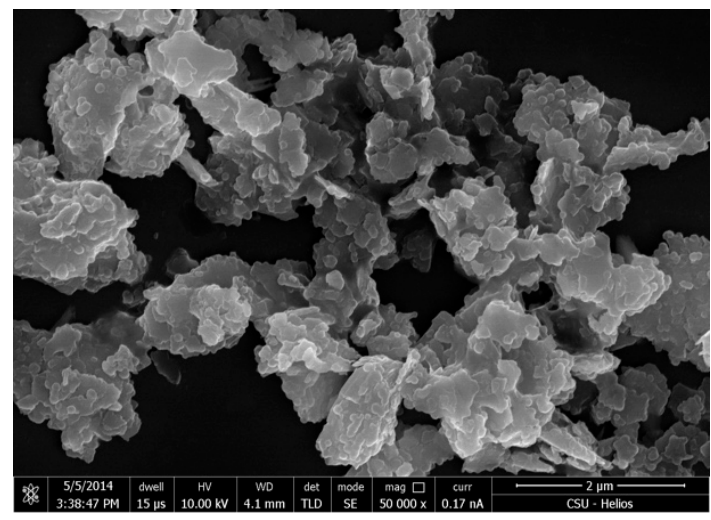

(b)

Figure 12. SEM micrographs of kaolinite with $2 \times 10^{-4} \mathrm{M}$ quaternary ammonium salts under alkaline condition using DTAC (a) and CTAC (b).

The edge face of the kaolinite particles was negatively charged at neutral and alkaline conditions, and the quaternary ammonium salts adsorbed on the edge surface by electrostatic adsorption. Kaolinite formed aggregation between the edge planes via the interaction effects of their non-polar hydrocarbon chains (Figures 11a and 12).

By comparing Figure 11 a with 11 b, it can be observed that the aggregation of the CTAC was smaller than that of DTAC at a concentration of $1.2 \times 10^{-3} \mathrm{M}$. This may be a result of the double lay adsorption that occurred between CTAC on the kaolinite surface. Thus, the hydrophobicity of kaolinite decreased as the kaolinite particles began to disperse.

As shown in Figure 12, compared with CTAC, the aggregation of kaolinite with DTAC was not much more effective at alkaline conditions. The results indicate that the longer the quaternary ammonium carbon chain, the stronger the effect it had on the aggregation of kaolinite, as well as acting to increase the sedimentation yield of the kaolinite.

\section{Conclusions}

This research has systematically studied the effects of three quaternary ammonium salts (i.e., DTAC, TTAC, and CTAC) on the aggregation and dispersion behaviors of kaolinite and quartz. The main outcomes can be described as follows:

(1) In the absence of reagents, the kaolinite particles showed an improved aggregation behavior in neutral and acid conditions, at which the sedimentation yield of kaolinite was over $90 \%$. Under the same experimental conditions, the quartz particles exhibited a comparatively lower aggregation behavior, and their sedimentation yield was less than $60 \%$.

(2) Except for CTAC, the additions of DTAC and TTAC increased the aggregation of the kaolinite and quartz particles in neutral and alkaline conditions. The aggregation yields of both minerals were increased significantly with the increasing the concentration of DTAC and TTAC. However, under the same conditions, the increasing concentration of CTAC resulted in an increase in the dispersion of kaolinite and quartz particles.

(3) In neutral and alkaline conditions, increasing the concentration of the quaternary ammonium salts increased the Zeta potentials as well as the adsorbed amounts of all three salts on the two minerals. Moreover, the effect of CTAC on the adsorption amounts and Zeta potentials of two minerals was much greater than those of DTAC and TTAC. The greater affinity of CTAC towards the minerals was mainly due to its longer carbon chain compared to that of DTAC and TTAC; the longer the carbon chain, the greater the effect on the Zeta potential and adsorbed amount on the kaolinite and quartz surface. 
(4) The aggregation of kaolinite and quartz particles in the presence of quaternary ammonium salts mainly occurred either from basal to basal, or basal to edge planes in acidic conditions, whereas that in alkaline and neutral conditions mainly occurred between the basal planes.

Author Contributions: Conceptualization, H.J.; Writing-Original Draft Preparation, G.X., K.H., and J.X.; Writing-Review \& Editing, G.X., H.J., L.X., and S.A.K.

Funding: The authors of this paper proudly acknowledge the financial support from the National Natural Science Foundation of China (grant nos. 51674207, 50974134, and 51304162) and the Key Laboratory of Hunan Province for Clean and Efficient Utilization of Strategic Calcium-Containing Mineral Resources (no. 2018TP1002).

Conflicts of Interest: The authors declare no conflict of interest.

\section{References}

1. Conceição, S.; Santos, N.; Velho, J.; Ferreira, J.; Santos, N.; Ferreira, J. Properties of paper coated with kaolin: The influence of the rheological modifier. Appl. Clay Sci. 2005, 30, 165-173. [CrossRef]

2. Murray, H.H.; Kogel, J.E. Engineered clay products for the paper industry. Appl. Clay Sci. 2005, 29, $199-206$. [CrossRef]

3. Nithitanakul, M. Polymer layer silicate nanocomposites: Linear PEO and highly brancheddendrimer for organic wastewater treatment. Rev. Adv. Mater. 2003, 5, 187-192.

4. Vahidhabanu, S.; Karuppasamy, D.; Adeogun, A.I.; Babu, B.R. Impregnation of zinc oxide modified clay over alginate beads: A novel material for the effective removal of congo red from wastewater. RSC Adv. 2017, 7, 5669-5678. [CrossRef]

5. Gu, S.; Kang, X.; Wang, L.; Lichtfouse, E.; Wang, C. Clay mineral adsorbents for heavy metal removal from wastewater: A review. Environ. Chem. Lett. 2018, 17, 629-654. [CrossRef]

6. Chang, P.-H.; Li, Z.; Jean, J.-S.; Jiang, W.-T.; Wang, C.-J.; Lin, K.-H. Adsorption of tetracycline on 2:1 layered non-swelling clay mineral illite. Appl. Clay Sci. 2012, 67-68, 158-163. [CrossRef]

7. Galindo, A.L.; Viseras, C.; Cerezo, P. Compositional, technical and safety specifications of clays to be used as pharmaceutical and cosmetic products. Appl. Clay Sci. 2007, 36, 51-63.

8. Götze, J. Chemistry, textures and physical properties of quartz-Geological interpretation and technical application. Miner. Mag. 2009, 73, 645-671. [CrossRef]

9. Liu, P.; Niu, L.; Tao, X.; Li, X.; Zhang, Z.; Yu, L. Preparation of superhydrophobic-oleophilic quartz sand filter and its application in oil-water separation. Appl. Surf. Sci. 2018, 447, 656-663. [CrossRef]

10. Oats, W.J.; Ozdemir, O.; Nguyen, A.V. Effect of mechanical and chemical clay removals by hydrocyclone and dispersants on coal flotation. Miner. Eng. 2010, 23, 413-419. [CrossRef]

11. Ma, X.; Bruckard, W.; Holmes, R. Effect of collector, $\mathrm{pH}$ and ionic strength on the cationic flotation of kaolinite. Int. J. Miner. Process. 2009, 93, 54-58. [CrossRef]

12. Hu, Y.; Liu, X.; Xu, Z. Role of crystal structure in flotation separation of diaspore from kaolinite, pyrophyllite and illite. Miner. Eng. 2003, 16, 219-227. [CrossRef]

13. Hu, Y.; Wei, S.; Hao, J.; Miller, J.; Fa, K. The anomalous behavior of kaolinite flotation with dodecyl amine collector as explained from crystal structure considerations. Int. J. Miner. Process. 2005, 76, 163-172. [CrossRef]

14. Liu, C.; Hu, Y.; Feng, A.; Guo, Z.; Cao, X. The behavior of $N, N$-dipropyl dodecyl amine as a collector in the flotation of kaolinite and diaspore. Miner. Eng. 2011, 24, 737-740. [CrossRef]

15. Zhang, N.; Nguyen, A.V.; Zhou, C. A review of the surface features and properties, surfactant adsorption and floatability of four key minerals of diasporic bauxite resources. Adv. Colloid Interface Sci. 2018, 254, 56-75. [CrossRef] [PubMed]

16. Chorom, M.; Rengasamy, P. Dispersion and zeta potential of pure clays as related to net particle charge under varying $\mathrm{pH}$, electrolyte concentration and cation type. Eur. J. Soil Sci. 1995, 46, 657-665. [CrossRef]

17. Gupta, V.; Hampton, M.A.; Stokes, J.R.; Nguyen, A.V.; Miller, J.D. Particle interactions in kaolinite suspensions and corresponding aggregate structures. J. Colloid Interface Sci. 2011, 359, 95-103. [CrossRef] [PubMed]

18. Zbik, M. SEM evidence of structural re-arrangement from gelling to aggregation in Birdwood kaolinite. Colloids Surfaces A Physicochem. Eng. Asp. 2006, 287, 191-196. [CrossRef] 
19. Rao, F.; Ramirez-Acosta, F.J.; Sánchez-Leija, R.J.; Song, S.; Lopez-Valdivieso, A. Stability of kaolinite dispersions in the presence of sodium and aluminum ions. Appl. Clay Sci. 2011, 51, 38-42. [CrossRef]

20. Lagaly, G.; Ziesmer, S. Colloid chemistry of clay minerals: The coagulation of montmorillonite dispersions. Adv. Colloid Interface Sci. 2003, 100-102, 105-128. [CrossRef]

21. Yang, F.; Sun, W.; Hu, Y.; Long, S. Cationic flotation of scheelite from calcite using quaternary ammonium salts as collector: Adsorption behavior and mechanism. Miner. Eng. 2015, 81, 18-28. [CrossRef]

22. Jiang, H.; Liu, G.; Hu, Y.; Xu, L.; Yu, Y.; Xie, Z.; Chen, H. Flotation and adsorption of quaternary ammonium salts collectors on kaolinite of different particle size. Int. J. Min. Sci. Technol. 2013, 23, 249-253. [CrossRef]

23. Kewu, W. The crystal structure and surface property of kaolinite. Non Met. Mines 1992, 01, 48-53.

24. Chen, Z.-Y.; Li, W.X.; Chen, X.Q.; Chen, X.Q.; Ma, J.W. Overview of the alumina silica crystal structure in bauxite. Light Met. 2008, 12, 6-9.

25. Goumans, T.P.; Wander, A.; Brown, W.A.; Catlow, C.R.A. Structure and stability of the (001) alpha-quartz surface. Phys. Chem. Chem. Phys. 2007, 9, 2146-2152. [CrossRef] [PubMed]

26. Zhang, X.-P.; Hu, Y.H.; Huang, H.J.; Deng, M.J. Aggregation behavior of ultrafine kaolinite in water. J. China Univ. Min. Technol. 2007, 04, 514-517.

27. Atkin, R.; Craig, V.; Wanless, E.; Biggs, S.; Craig, V.; Wanless, E. Mechanism of cationic surfactant adsorption at the solid-aqueous interface. Adv. Colloid Interface Sci. 2003, 103, 219-304. [CrossRef]

28. Tian, J.; Xu, L.; Deng, W.; Jiang, H.; Gao, Z.; Hu, Y. Adsorption mechanism of new mixed anionic/cationic collectors in a spodumene-feldspar flotation system. Chem. Eng. Sci. 2017, 164, 99-107. [CrossRef]

29. Fan, A.; Somasundaran, P.; Turro, N.J. Adsorption of Alkyltrimethylammonium Bromides on Negatively Charged Alumina. Langmuir 1997, 13, 506-510. [CrossRef]

30. Zbik, M.; Horn, R.G. Hydrophobic attraction may contribute to aqueous flocculation of clays. Colloids Surfaces A Physicochem. Eng. Asp. 2003, 222, 323-328. [CrossRef]

31. Zbik, M.; Smart, R. Dispersion of kaolinite and talc in aqueous solution: Nano-morphology and nano-bubble entrapment. Miner. Eng. 2002, 15, 277-286. [CrossRef]

(C) 2019 by the authors. Licensee MDPI, Basel, Switzerland. This article is an open access article distributed under the terms and conditions of the Creative Commons Attribution (CC BY) license (http://creativecommons.org/licenses/by/4.0/). 